\title{
Keamanan Hair Tonic Ekstrak Etanol, Fraksi Etanol, dan Fraksi Kloroform-Metanol dari Kayu Secang (Caesalpinia sappan L.) dengan Metode Uji Iritasi Primer dan HET-CAM
}

\author{
Dina Yuspita Sari $^{1}$ and Ika Ristia Rahman ${ }^{1}$ \\ ${ }^{1}$ Program Studi D III Farmasi, Akademi Farmasi Yarsi, Jalan Panglima Aim No. 2, Pontianak, Indonesia 78232 \\ Reception date of the manuscript: 24 Juli 2021 \\ Acceptance date of the manuscript: 14 Agustus 2021 \\ Publication date: 31 Desember 2021
}

\begin{abstract}
Hair tonic is a hair care cosmetic to reduce hair loss, stimulate, and increase hair volume. Secang wood (Caesalpinia sappan L.) has the potential to be developed as an active substance in hair tonic products because it contains flavonoids, polyphenols, including brazilin which are used to treat damage hair. To ensure the safety of hair tonic products, safety tests are required, including skin and eye irritation tests. This study aims to determine the safety of hair tonic formula of ethanol extract, ethanol fraction, and chloroform-methanol fraction from sappan wood. Ethanol extract, ethanol fraction, and chloroform-methanol fraction of sappan wood were formulated into hair tonic preparations. The hair tonic safety test includes: primary irritation test and eye irritation test using HET-CAM method. Based on the primary irritation test, the score of erythema and edema on the skin obtained a PII value of 0 (non-irritating category). The HET-CAM test on the three hair tonic formulas, positive control and negative control, showed that the positive control (lactic acid) resulted in an irritation score of 9.51 (strong irritation category); negative control $(\mathrm{NaCl} 0.9 \%)$ and the three hair tonic formulas had an irritation score of 0 (no irritation category). This indicates that the hair tonic formula from ethanol extract, ethanol fraction, and chloroform-methanol fraction of sappanwood is not irritating and safe to use.
\end{abstract}

Keywords-HET-CAM, primary irritation test, sappan wood.

\begin{abstract}
Abstrak - Hair tonic merupakan kosmetik perawatan rambut yang berfungsi untuk mengurangi rambut rontok, merangsang, dan meningkatkan volume rambut. Kayu secang (Caesalpinia sappan L.) merupakan tanaman yang potensial dikembangkan menjadi zat aktif pada produk hair tonic karena mengandung senyawa flavonoid, pilofenol, termasuk brazilin yang dimanfaatkan untuk merawat rambut dari kerusakan. Untuk menjamin keamanan produk hair tonic, diperlukan uji keamanan, meliputi uji iritasi pada kulit dan mata. Penelitian ini bertujuan untuk menentukan keamanan formula hair tonic ekstrak etanol, fraksi etanol, dan fraksi kloroform-metanol dari kayu secang. Ekstrak etanol, fraksi etanol, dan fraksi kloroform-metanol kayu secang diformulasi ke dalam sediaan hair tonic. Pengujian keamanan hair tonic, meliputi: uji iritasi primer dan uji iritasi mata menggunakan metode HET-CAM. Berdasarkan uji iritasi primer, skor eritma dan edema pada kulit didapatkan nilai PII 0 (kategori tidak mengiritasi). Uji HET-CAM pada ketiga formula hair tonic, kontrol positif dan kontrol negatif, menunjukkan bahwa pada kontrol positif (asam laktat) menghasilkan skor iritasi sebesar 9,51 (kategori iritasi kuat); kontrol negatif $(\mathrm{NaCl} 0,9 \%)$ dan ketiga formula hair tonic memiliki skor iritasi 0 (kategori tidak terjadi iritasi). Hal tersebut mengindikasikan bahwa formula hair tonic dari ekstrak etanol, fraksi etanol, dan fraksi kloroform-metanol kayu secang tidak mengiritasi dan aman digunakan.
\end{abstract}

Kata Kunci-HET-CAM, kayu secang, uji iritasi primer

\section{Pendahuluan}

Kosmetika rambut merupakan produk yang membantu meningkatkan penampilan dan membantu mengatasi masalah pada rambut dan kulit kepala (Dias 2015). Pengetahuan tentang kosmetik rambut dan prosedur estetika rambut diperlukan dalam memformulasi produk kosmetika rambut (Cruz et al. 2016). Pigmentasi batang rambut merupakan salah sa-

Penulis koresponden: Dina Yuspita Sari, E-mail: dinayuspitasari7@gmail.com tu masalah rambut yang disebabkan oleh sinar UV (Utami, Djajadisastra, and Saputri 2017). Adanya melanin di dalam bulbus rambut dapat membantu melindungi sel akibat radikal bebas oleh reactive oxygen species (ROS) (Harkey 1993), sehingga diperlukan produk yang dapat mempertahankan dan mendukung fungsi melanin rambut.

Hair tonic merupakan kosmetik perawatan rambut yang berfungsi untuk mengurangi rambut rontok, merangsang, dan meningkatkan volume rambut. Komponen utama dalam sediaan hair tonic adalah pelarut dan bahan aktif (0,05-0,5\%) (Indriaty, Indrawati, and Taurhesia 2018). Pelarut yang paling umum digunakan adalah air (30-50\%) dan alkohol (50- 
$70 \%)$. Zat aktif yang digunakan dapat berupa bahan kimia sintesis ataupun berasal dari tanaman atau ekstrak tanaman (Schrader and Domsch 2005), berfungsi untuk membersihkan, mencegah atau untuk membasmi ketombe, memperbaiki sirkulasi darah di kulit kepala dan merangsang pertumbuhan rambut (Wong 2013).

Kayu secang (Caesalpinia sappan L.) merupakan salah satu tanaman yang potensial dikembangkan menjadi zat aktif pada produk kosmetik. Kayu secang mengandung senyawa bioaktif seperti homoisoflavonoid dan fenol (seperti brazilin dan brazilein) (Vardhani 2019). Senyawa flavonoid dan fenol yang terkandung mempunyai aktivitas antioksidan. Senyawa antioksidan dari bahan alami atau tumbuhan memiliki kelebihan dibandingkan dengan bahan sintetik karena residu yang dihasilkan lebih mudah terdegradasi (Sari dan Suhartati et al. 2010). Ekstrak etanol kayu secang terbukti aman dan tidak menunjukkan toksisitas akut atau subakut pada tikus jantan dan betina (Indrawati, Syahrin, and Irpan 2017).

Senyawa antioksidan brazilin yang terkandung dalam kayu secang dapat dimanfaatkan sebagai bahan aktif pada produk hair tonic untuk merawat rambut dari kerusakan. Berdasarkan penelitian terdahulu, ekstraksi kayu secang menggunakan pelarut etanol menghasilkan ekstrak yang lebih stabil dibandingkan menggunakan air dan n-heksana (Padmaningrum, Marwati, and Wiyarsi 2012), dengan hasil spectrum IR memiliki gugus fungsi-OH dan ikatan terkonjugasi (Rina 2013). Poses fraksinasi menggunakan metode partisi bertujuan untuk memperoleh fraksi etanol yang telah terpisahkan dari komponen non polar lainnya (Sarker, Latif, and Gray 2006), dimana hasil penelitian sebelumnya nilai rendemen fraksi etanol terhadap ekstrak etanol kayu secang adalah sebesar 83, $39 \%$ (Sari, Widiyantoro, and Alimuddin 2018). Pemisahan senyawa brazilin memberikan hasil terbaik menggunakan fase gerak kloroform-metanol (5:1) dengan fase diam silika gel (Hangoluan 2011).

Untuk menjamin keamanan produk hair tonic, diperlukan uji keamanan, meliputi uji iritasi pada kulit dan mata. Metode uji iritasi yang dapat dilakukan adalah uji iritasi primer kualitatif (Toding and Zulkarnain 2015). Pemeriksaan sensitivitas kulit ini merupakan pemeriksaan awal untuk mendeteksi reaksi alergi yang mungkin disebabkan oleh hair tonic (Wong 2013). Sementara, uji iritasi pada mata dapat dilakukan menggunakan metode Hen's egg test-chorioallantoic membrane (HET-CAM) (Yuliani, Rahmadani, and Istyastono 2016). Tujuan penelitian ini adalah menentukan keamanan formula hair tonic ekstrak etanol, fraksi etanol, dan fraksi kloroform-metanol dari kayu secang.

\section{TABEL 1: FORMULA HAIR TONIC}

\begin{tabular}{ll}
\hline Bahan & Formula (\%) \\
\hline Zat aktif* & 0,1 \\
Menthol & 0,5 \\
Propilenglikol & 7 \\
Polysorbate 80 & 1 \\
Butilhidroksitoluen (BHT) & 0,1 \\
Natrium benzoat & 0,5 \\
Isopropil alkohol & 60 \\
Citrus oil & 0,1 \\
Air & ad 100 \\
\hline
\end{tabular}

\section{BAHAN DAN METODE}

\section{Bahan dan Alat}

Bahan-bahan yang digunakan adalah kayu secang, methanol teknis, etanol $96 \%$ teknis, n-heksana teknis, kloroform teknis, silika gel 60 (Merck 230-400 mesh), menthol, propilenglikol, polysorbate 80 , butilhidroksitoluen, natrium benzoat, isopropyl alcohol, citrus oil, air, natrium klorida 0,9\% (Sanbe), natrium lauril sulfat, kasa steril, dan plester.

Hewan uji adalah telur ayam leghorn dan kelinci albino galur New Zealand. Alat-alat yang digunakan adalah peralatan kaca, pipet ukur, neraca analitik (Sartorius BL 210S), kertas saring, rotary evaporator (Dragon LAB RE-10 Pro), chamber, pelat KLT silika gel 60 F-254 (Merck), kromatografi kolom vakum (KKV), pH-meter, oven, viskometer Brookfield (Ntech), alat cukur, incubator (Gemmyco Digital), termometer, dan gunting steril.

\section{Metode \\ 1. Ekstraksi dan Partisi}

$2 \mathrm{~kg}$ serbuk kayu secang dimaserasi menggunakan etanol 96\%. Partisi dilakukan menggunakan n-heksana dan etanol (1:1) (Sari, Widiyantoro, and Alimuddin 2018)

\section{Pemisahan}

10 g Fraksi etanol dielusi menggunakan gradien eluen, yaitu: kloroform, kloroform:metanol (5:1), dan metanol. Identifikasi menggunakan KLT silika gel 60 F254 dengan eluen kloroform:metanol (5:1), dideteksi menggunakan lampu UV pada 254 dan $366 \mathrm{~nm}$ (Sari, Widiyantoro, and Alimuddin 2018).

\section{Formulasi hair tonic}

Formula hair tonic tersaji pada Tabel 1.

\section{Uji Iritasi Primer}

Hewan uji yang digunakan adalah kelinci albino galur New Zeland berkelamin jantan dengan metode patch test tertutup (Toding and Zulkarnain 2015). 24 jam sebelum perlakuan, bulu pada bagian punggung di cukur (Dewantara et al. 2015) dengan ukuran 2 × $2 \mathrm{~cm}(28 ; 25) .0,5 \mathrm{~mL}$ bahan uji diberikan dengan cara mengoleskan sediaan uji pada area uji. Area yang diolesi ditutup dengan kain kasa steril yang dilapisi plastik, kemudian ditutup lagi dengan hypafix dan diberi plester (Adhi Pradana and Hernawan Nugroho 2016). Setelah 24 jam perlakuan, perban dibuka dan area uji dibersihkan dengan air untuk menghilangkan sisa bahan uji. Pada jam ke 24, 48 dan 72, area uji kemudian diperiksa dan diamati perubahannya sebagai reaksi kulit terhadap bahan uji dan dinilai dengan cara memberi skor 0 sampai 4 tergantung dari tingkat keparahan reaksi kulit yang dilihat (eritema dan edema) (Dewantara et al. 2015), kemudian dicocokkan pada table skor iritasi (Tabel 2).

Hasil yang didapat kemudian dihitung untuk mendapatkan indeks iritasi primer kulit sebagai Primary Irritation Index $(P I I): P I I=(A-B) / C$ Dimana A adalah jumlah skor eritema dan edema dari semua sampel (pada 24, 48 dan 72 jam) dibagi dengan banyaknya pengamatan, $\mathrm{B}$ adalah banyaknya nilai eritema dan edema semua kontrol (pada 24, 48 dan 72 jam) dibagi dengan banyaknya pengamatan, dan $\mathrm{C}$ adalah jumlah hewan. PII saat itu dikategorikan berdasarkan kriteria ISO 10993-1013 (Tabel 3) (Aditya Nugraha et al. 2020). 
Tabel 2: Skor Penilaian Reaksi Kulit Kelinci

\begin{tabular}{lc}
\hline Pembentukan Eritema dan Edema & Skor \\
\hline Eritema & \\
Tidak terbentuk eritema & 0 \\
Eritema sangat sedikit & 1 \\
Eritema terlihat jelas & 2 \\
Eritema sedang sampai berat & 3 \\
Eritema parah sampai pembentukan eschar yang menghambat penilaian eritema & 4 \\
\hline Edema & \\
Tidak terbentuk edema & 0 \\
Edema sangat kecil & 1 \\
Edema kecil (daerah batas terlihat, jelas) & 2 \\
Edema tingkat menengah (area meningkat sekitar 1 mm) & 3 \\
Edema parah (area meningkat lebih dari 1 mm dan melebar & 4 \\
\hline
\end{tabular}

TABEL 3: KATEGORI RESPON IRITASI

\begin{tabular}{ll}
\hline Indeks Iritasi & Kategori Respon \\
\hline $0,0-0,4$ & Tidak terjadi iritasi; iritasi ringan \\
$0,5-1,9$ & Iritasi menengah \\
$2,0-4,9$ & Iritasi \\
$5,0-8,0$ & Iritasi kuat \\
\hline
\end{tabular}

TABEL 4: . KATEgori IRITASi HET-CAM IRITASI HET-CAM

\begin{tabular}{ll}
\hline Skor iritasi HET-CAM & Kategori iritasi \\
\hline 0,9 & Tidak terjadi iritasi; iritasi ringan \\
$1,0-4,9$ & Iritasi menengah \\
$5,0-8,9$ & Iritasi \\
$9,0-21$ & Iritasi kuat \\
\hline
\end{tabular}

TABEL 5: KARAKTERISTIK EKSTRAK ETANOL, FRAKSI ETANOL DAN DAN FRAKSI KLOROFORM-METANOL DARI KAYU SECANG

\begin{tabular}{lccc}
\hline \multirow{2}{*}{ Sampel } & Karakteristik & & \\
\cline { 2 - 4 } & Warna & Bau & Bentuk \\
\hline Ekstrak etanol & Jingga kecoklatan & Khas & Ekstrak kering, padatan \\
Fraksi etanol & Jingga kecoklatan & Khas & Fraksi kering, padatan \\
Fraksi klororom-metanol & Jingga kecoklatan & Khas & Fraksi kering, padatan \\
\hline
\end{tabular}

\section{Hen's Egg Test Chorioallantoic Membrane (HET- CAM)}

Telur ayam leghorn yang telah dibuahi dimasukkan dalam inkubator dengan suhu 37C. Rongga udara telur dipastikan berada di sebelah atas. Telur dirotasi selama 10 hari. Pada hari kesepuluh telur diteropong, telur yang tidak mengandung embrio hidup dibuang. Rongga udara telur ditandai. Rongga telur yang telah ditandai, digunting cangkang terluarnya dengan menggunakan gunting steril. Untuk mempermudah proses ini cangkang dilunakkan dengan larutan $\mathrm{NaCl}$ 0,9\% steril. Setelah cangkang terluar dibuang, membran terluar telur dibasahi dengan larutan $\mathrm{NaCl} 0,9 \%$ hangat dan dimasukkan kembali ke dalam inkubator selama 5-20 menit. Setelah membran terluar diambil, dipilih telur yang tidak mengalami kerusakan CAM akibat proses tersebut. Sebanyak $300 \mathrm{mg}$ sampel diletakkan pada CAM, diamkan 20 detik. Setelah 20 detik CAM segera dibersihkan dengan menggunakan $\mathrm{NaCl}$ $0,9 \%$ steril. Waktu pengamatan selama 300 detik dimulai segera setelah CAM bersih dari sampel. Percobaan dilakukan terhadap kontrol iritan (SLS), kontrol negative (air) dan formula hair tonic (Cazedey et al. 2009). Data yang didapat pa- da uji HET-CAM dihitung menggunakan rumus:

$$
T=\frac{(301-H)}{300} \times 5+\frac{(301-L)}{300} \times 7+\frac{(301-C)}{300} \times 9 .
$$

Dimana T adalah skor iritasi HET-CAM, H adalah waktu (detik) terjadinya hyperemia, L adalah waktu (detik) terjadinya lisis, dan $\mathrm{C}$ adalah waktu (detik) terjadinya koagulasi pada CAM. haemoragia adalah peningkatan jumlah pembuluh darah sampai perdarahan pada CAM, lisis adalah pecahnya pembuluh darah pada CAM, dan koagulasi adalah pembekuan darah di sekitar CAM (Luepke and Kemper 1986) atau denaturasi protein intra dan ekstra vaskuler (Febriani, Elya, and Jufri 2016). Hasil yang didapat dari perhitungan kemudian dicocokan dengan nilai pada Tabel 4.

\section{HASIL}

Penelitian dilakukan dalam 2 (dua) tahap, yaitu persiapan sampel penelitian dan pengujian keamanan hair tonic, meliputi: uji iritasi primer dan uji iritasi mata menggunakan metode HET-CAM. 
TABEL 6: . KATEGORI IRITASI HET-CAM IRITASI HET-CAM

\begin{tabular}{|c|c|c|c|c|c|c|}
\hline \multirow[t]{2}{*}{ Formula } & \multicolumn{3}{|c|}{ Hasil } & \multicolumn{2}{|c|}{ Keterangan } & \multirow[t]{2}{*}{ Skor Iritas } \\
\hline & 24 jam & $48 \mathrm{jam}$ & $72 \mathrm{jam}$ & Eritema & Edema & \\
\hline FI (ekstrak etanol) & & & & - & - & 0 \\
\hline FII (fraksi etanol) & & & & - & - & 0 \\
\hline FIII (fraksi kloroform-etanol) & & & & - & - & 0 \\
\hline
\end{tabular}

Tabel 7: Hasil Uji Iritasi Formula Hair Tonic MenggunaKan Metode HeT-CAM

Perlakuan

Keterangan: FI: hair tonic ekstrak etanol; FII: hair tonic fraksi etanol; FIII: hair tonic fraksi kloroform-metanol; K+: kontrol positif (asam laktat); K-: kontrol negatif ( $\mathrm{NaCl} 0,9 \%)$; a: haemoragia; b: lisis

\section{Tahap Persiapan Sampel Penelitian}

a. Pembuatan simplisia

Kayu secang $(6 \mathrm{~kg})$ dibersihkan dan dikeringkan menggunakan oven sehingga didapatkan simplisia kering kayu secang sebanyak 5.487,94 g dengan kadar air sebesar 6,43\%.

\section{b. Ekstraksi}

Ekstraksi kayu secang dilakukan dengan cara maserasi menggunakan pelarut etanol $96 \%$, kemudian dipekatkan menggunakan rotary evaporator sehingga diperoleh ekstrak sebanyak $247,89 \mathrm{~g}$ dengan rendemen sebesar 4,52\%. Ekstrak kental etanol seberat 92,95 g dipartisi menggunakan $\mathrm{n}$ heksana sehingga diperoleh fraksi kental seberat $77,51 \mathrm{~g}$, dengan rendemen sebesar $1,62 \%$.

\section{c. Karakteristik ekstrak etanol, fraksi etanol, dan fraksi kloroform-metanol kayu secang.}

Ketiga sampel berwarna jingga-kecoklatan, berbau khas, dan berbetuk padatan kering. Adapun karakteristik dari eks- 
trak etanol, fraksi etanol dan fraksi kloroform-metanol kayu secang dapat dilihat pada Tabel 5.

\section{d. Formulasi hair tonic}

Ekstrak etanol, fraksi etanol, dan fraksi kloroformmetanol kayu secang dengan konsentrasi $0,1 \%$ kemudian diformulasi ke dalam sediaan hair tonic, menghasilkan hair tonic dengan warna merah muda (FI dan FII) dan merah mudakeunguan (FIII) (Gambar 1).

\section{Uji Iritasi Primer}

Uji ini dilakukan untuk melihat adanya iritasi primer, ditandai dengan adanya reaksi kulit terhadap iritan, yaitu eritema dan/atau edema (3,4) (Banerjee et al. 2013; Dewantara et al. 2015). Hasil uji iritasi kulit pada kelinci dapat dilihat pada Tabel 2. Ketiga formula hair tonic menunjukkan hasil tidak terjadi iritasi dengan skor iritasi (PII) sebesar 0.

\section{Uji Iritasi Mata Dengan Metode Hen's Egg Test Chorioallantoic Membrane.}

Pada uji ini digunakan telur ayam leghorn sebanyak 15 telur yang sebelumnya diinkubasi selama 10 hari pada suhu 37C, dan dilakukan pemeriksaan CAM yang mengandung embrio hidup. Hasil pengamatan dapat dilihat pada Tabel 3. Hasil uji HET-CAM pada ketiga formula hair tonic, kontrol positif dan kontrol negatif, menunjukkan bahwa pada kontrol positif (asam laktat) terjadi haemoragia pada detik ke 40 dan lisis pada detik ke 80, menghasilkan skor iritasi sebesar 9,51 (kategori iritasi kuat); kontrol negatif ( $\mathrm{NaCl} \mathrm{0,9 \% )} \mathrm{dan} \mathrm{keti-}$ ga formula hair tonic memiliki skor iritasi 0 (nol) (kategori tidak terjadi iritasi).

\section{Pembahasan}

\section{Tahap Persiapan Sampel Penelitian}

a. Pembuatan simplisia Proses pengeringan simplisia dilakukan untuk menghentikan reaksi enzimatis sehingga mengurangi resiko tumbuhnya jamur selama penyimpanan yang dapat menurunkan mutu simplisia. Kayu secang yang telah kering kemudian dirajang menjadi ukuran yang lebih kecil, setelah itu dilanjutkan dengan penghalusan menggunakan blender sampai didapat serbuk kasar kayu secang, tujuannya adalah untuk memperkecil ukuran partikel simplisia sehingga memperluas kontak simplisia dengan pelarut saat proses ekstraksi agar proses ekstraksi berlangsung optimal. b. Ekstraksi Ekstraksi kayu secang dilakukan dengan cara maserasi. Metode maserasi dipilih karena pelarut polar, seperti etanol merupakan pelarut yang baik untuk penarikan senyawa polifenol, flavonoid, termasuk senyawa bioaktif brazilin (Rasouli, Farzaei, and Khodarahmi 2017). Ekstrak kental etanol dipartisi menggunakan n-heksana. Tujuannya adalah untuk menghilangkan pengotor seperti lilin, klorofil, dan lemak (Febriani, Elya, and Jufri 2016). c. Karakteristik ekstrak etanol, fraksi etanol, dan fraksi kloroform-metanol kayu secang. Warna yang dihasilkan baik pada ekstrak maupun fraksi adalah jingga kecoklatan. Hal ini disebabkan oleh warna brazilin yang terkandung dalam kayu secang dalam pelarut etanol akan menghasilkan warna jingga-merah sampai kecoklatan dan stabil (tidak mudah berubah warna) Padmaningrum, Marwati, and Wiyarsi 2012). d. Formulasi hair tonic Formula hair tonic berwarna merah muda (FI dan FII) dan merah muda-keunguan (FIII), berbentuk larutan homogen.

\section{Uji Iritasi Primer}

Pengujian menggunakan patch test tertutup bertujuan untuk membandingkan perubahan kulit yang terjadi. Secara teoritis, skor eritema dan edema pada kulit yang diberikan senyawa iritan lebih besar daripada kulit yang tidak berikan senyawa iritan. Hasil dari dua kelompok tersebut kemudian digabungkan untuk mendapatkan Primary Irritation Index (PII) (Adhi Pradana and Hernawan Nugroho 2016).

Iritasi kulit yang mungkin timbul disebabkan oleh reaksi peradangan karena pelepasan sitokin proinflamasi dari keratinosit. Biasanya terjadi sebagai respon terhadap rangsangan kimia yang menyebabkan gangguan pada barrier kulit, perubahan pada sel epidermis, dan pelepasan sitokin. Gejala yang timbul pada fase akut adalah eritema, edema, pengerasan kulit, nyeri tekan, vesikel, atau pustule (Aditya Nugraha et al. 2020). Pada ketiga formula dan kontrol negatif tidak menunjukkan reaksi iritasi, dengan perhitungan Primary Irritation Index (PII) menghasilkan skor iritasi nol (tidak menimbulkan iritasi kulit).

Hasil tersebut menjelaskan bahwa ketiga formula hair tonic aman digunakan secara topikal pada kulit kepala. Adanya kandungan senyawa flavonoid dan fenol, termasuk brazilin dalam ekstrak polar kayu secang yang memiliki aktivitas antioksidan (Badami et al. 2003) menyebabkan ekstrak kayu secang dapat melindungi jaringan dari kerusakan, salah satunya peroksidasi lipid. Peroksidasi lipid ditemukan menjadi peristiwa patofisiologis penting dalam berbagai penyakit, termasuk kerusakan pada jaringan kulit (Sari dan Suhartati et al. 2010).

\section{Uji Iritasi Mata Dengan Metode Hen's Egg Test Chorioallantoic Membrane}

Metode HET-CAM merupakan metode alternatif untuk menguji adanya iritasi okular dengan menilai potensi iritasi pada konjungtiva. Iritasi akut yang terjadi diasumsikan serupa dengan efek yang terjadi pada mata kelinci (Silva, Rougier, and Dossou 1992). Membran chorioallantoi (CAM) adalah jaringan lengkap yang mengandung arteri, vena dan kapiler mirip dengan uji Draize dan ideal untuk studi iritasi mata (Cazedey et al., 2009). Metode HET-CAM menggunakan CAM digunakan untuk mengetahui keamanan suatu zat dengan mengevaluasi hiperemia, lisis, dan koagulasi setelah 5 menit pemberian larutan/padatan uji (Yuliani et al., 2016). Efek iritasi pada pembuluh darah CAM dan albumin dinilai menggunakan skor iritasi berdasarkan waktu yang dibutuhkan untuk setiap parameter pengamatan (skor maksimum 21) (Cazedey et al. 2009).

Formula hair tonic mengandung isopropil alkohol, natrium benzoat, butilhidroksitoluen, polysorbate 80 , propilenglikol, menthol, citrus oil, akuades dan ekstrak etanol kayu secang (FI), fraksi etanol kayu secang (FII), dan fraksi kloroform-metanol (FIII) sebagai zat aktif. Isopropil alkohol merupakan pelarut dalam formulasi farmasi topikal di mana dapat bertindak sebagai iritan lokal. Butilhidroksitoluen sebagai antioksidan secara umum merupakan zat noniritan dan nonsensitif. Menthol merupakan zat yang noniritan namun dapat menimbulkan hipersensitifitas. Polysorbate 80 merupakan surfaktan yang bersifat nontoksik dan noniritan. Propilengikol dalam formula bertindak sebagai kosolven, dimana pada sediaan topikal bersifat mengiritasi ringan, menyebabkan iritasi lokal pada selaput lendir pada mata, luka pa- 


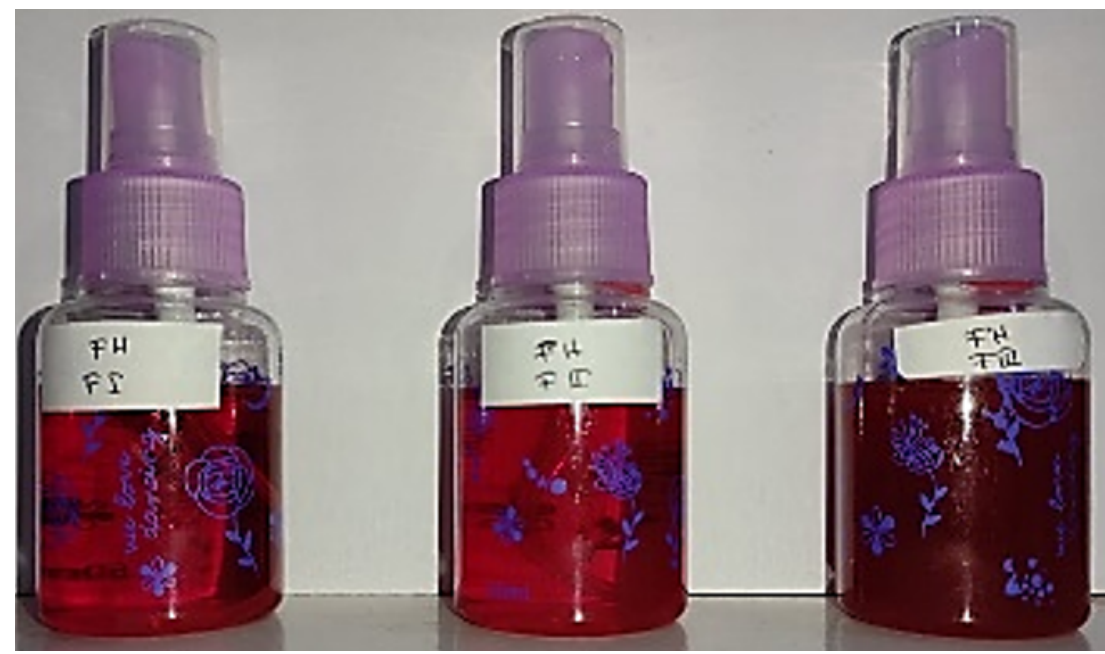

Gambar. 1: Formula hair tonic kayu secang: FI (ekstrak etanol); FII (fraksi etanol); dan FIII (fraksi kloroform-metanol)

da kornea mata, serta kerusakan mata (Rowe, Sheskey, and Quinn 2009). Hasil pengamatan CAM pada ketiga formula hair tonic, kontrol positif dan kontrol negatif, menunjukkan bahwa pada kontrol positif (asam laktat), terjadi haemoragia pada detik ke-40 dan lisis pada detik ke-80, tanpa koagulasi, dengan skor iritasi sebesar 9,51 (kategori iritasi kuat). Pada kontrol negatif $(\mathrm{NaCl}$ 0,9\%) dan ketiga formula hair tonic, tidak terjadi iritasi, dengan skor iritasi 0 (nol) (kategori tidak terjadi iritasi). Hal tersebut mengindikasikan bahwa formula hair tonic dari ekstrak etanol, fraksi etanol, dan fraksi kloroform-metanol kayu secang tidak mengiritasi dan aman digunakan.

\section{UCAPAN TERIMA KASIH}

Penulis mengucapkan terima kasih kepada semua pihak yang telah membantu dan mendukung penulis melakukan penelitian dan penulisan karya tulis ilmiah ini.

\section{Daftar Pustaka}

Aditya Nugraha et al. 2020. "Acute Irritation of Tetracyclic C-4-Hydroxyphenylcalics [4] Pyrogalolarene on Skin of Albino Rabbits.” Indonesian Journal of Pharmacology and Therapy 1(1): 15-21.

Badami, Shrishailappa et al. 2003. "Antioxidant Activity of Caesalpinia Sappan Heartwood.” Biological and Pharmaceutical Bulletin 26(11): 1534-37.

Banerjee, Subham et al. 2013. "Acute Dermal Irritation, Sensitization, and Acute Toxicity Studies of a Transdermal Patch for Prophylaxis against $( \pm)$ Anatoxin-a Poisoning." International Journal of Toxicology 32(4): 308-13.

Cazedey, Edith Cristina Laignier et al. 2009. "Corrositex ${ }^{\circledR}$, BCOP and HET-CAM as Alternative Methods to Animal Experimentation.” Brazilian Journal of Pharmaceutical Sciences 45(4): 759-66.

Cruz, Célia F. et al. 2016. "Human Hair and the Impact of Cosmetic Procedures: A Review on Cleansing and Shape-Modulating Cosmetics." Cosmetics 3(3): 1-22.

Dewantara, I.G.N.A et al. 2015. "Uji Eritema Dan Edema Secara in Vivo Pada Natrium Lauril Sulfat $10 \%$.' Jurnal Farmasi Udayana Volume Iv, Nomor 2 4(2): 1-21.
Dias, Maria Fernanda Reis Gavazzoni. 2015. "Hair Cosmetics: An Overview." International Journal of Trichology 7(1): 2-15.

Febriani, Amelia, Berna Elya, and Mahdi Jufri. 2016. "Uji Aktivitas Dan Keamanan Hair Tonic Ekstrak Daun Kembang Sepatu (Hibiscus Rosa-Sinensis) Pada Pertumbuhan Rambut Kelinci.” Jurnal Farmasi Indonesia 8 No 1(1): 259-70.

Hangoluan, B. Y. M. 2011. "Pengembangan Metode Isolasi Brazilin Dari Kayu Secang (Caesalpinia Sappan).” : 24.

Harkey, M. R. 1993. "Anatomy and Physiology of Hair." Forensic Science International 63(1-3): 9-18.

Hernawan Nugroho. 2016. "Uji Stabilitas Dan Uji Iritasi Primer Sediaan Kosmetik Mikroemulsi Vitamin C Palmitat (Ascorbyl Pamitate)." Jurnal Ilmiah Farmasi 12(1): $10-21$.

Indrawati, T., A. Syahrin, and Irpan. 2017. "Preparation of Demipermanent and Semipermanent Hair Dyes Gels from Ethanol Extract of Caesalpinia Sappan L. Using Carbomer as Gelling Agent." AIP Conference Proceedings 1862(July).

Indriaty, Sulistiorini, Teti Indrawati, and Shelly Taurhesia. 2018. "Formulation and Test Activities of Hair Tonic with a Combination of the Aqueous Extracts of Aloe Vera ( Aloe Vera L.) and Licorice (Glycyrrhiza Glabra L.)." Pharmaciana 8(1): 33.

Luepke, NP, and FH Kemper. 1986. "The HET-CAM Test: An Alternative to the Draize Eye Test." Food Chem Toxicol 24(6): 495-96.

Luliana, Sri, Rise Desnita, and Rani Rawinda. 2018. "Formulation of Hair Tonic of Meniran (Phyllanthus Niruri L.) Ethanol Extract as Hair Grower in Male White Rat (Rattus Norvegicus) Wistar Strain.” International Journal for Pharmaceutical Research Scholars 7(3): 136-45.

Padmaningrum, Regina Tutik, Siti Marwati, and Antuni Wiyarsi. 2012. "Karakter Ekstrak Zat Warna Kayu Secang (Caesalpinia Sappan L) Sebagai Indikator Titrasi Asam Basa." Kimia 3(1): 1-9.

Rasouli, Hassan, Mohammad Hosein Farzaei, and Reza Khodarahmi. 2017. "Polyphenols and Their Benefits: A Review." International Journal of Food Properties 20(00): 1700-1741. 
https://doi.org/10.1080/10942912.2017.1354017.

Rina, Oktaf. 2013. "Identifikasi Senyawa Aktif Dalam Ekstrak Etanol Kayu Secang ( Caesalpinia Sappan . L .)." Prosiding Semirata FMIPA Universitas Lampung: 215-18.

Rowe, Raymond c, Paul J Sheskey, and Marian E Quinn. 2009. Sixth Edit Handbook of Pharmaceutical Excipients. Sixth Edit. Washington: Pharmaceutical Press and American Pharmacists Association.

Sari dan Suhartati, Ramdana et al. 2010. "Secang (Caesalpinia Sappan L.): Tumbuhan Herbal Kaya Antioksidan.” : 57-68.

Sari, Dina Yuspita, Ari Widiyantoro, and Andi Hairil Alimuddin. 2018. "Isolasi Brazilin Dari Kayu Secang (Caesalpinia Sappan L.) Dan Formulasinya Untuk Lipstik Batang.” Jurnal Ilmu Dan Terapan Kimia 3(1): 1-15.

Sarker, satyajit d, Zahid Latif, and alexander i Gray. 2006. Natural Products Isolation. second. eds. satyajit d Sarker, Zahid Latif, and alexander i Gray. new jersey: humana press.

Schrader, Karlheinz, and Andreas Domsch. 2005. Cosmetology-Theory and Practitice. ii. eds. Karlheinz Schrader and Andreas Domsch. augsburg: verlag fur chemische industrie.

Silva, O, A Rougier, and K. G Dossou. 1992. "The HETCAM Test: A Study of Irritation Potential of Chemicals and Formulations (L'OREAL)." Altern. Labor. Anim 20(3): 432-37.

Toding, Lusty Grace, and A. Karim Zulkarnain. 2015. “OPTIMIZING FORMULA AND QUALITATIVE PRIMARY IRRITATION TEST IN FEMALE WHITE RABBIT OF W/O CREAM THE ETHANOLIC EXTRACT OF PHALERIA FRUIT [Phaleria Macrocarpa (Scheff.) Boerl.]." Majalah Farmaseutik 11(2): 21-27.

Utami, Sheila Meitania, Joshita Djajadisastra, and Fadlina Chany Saputri. 2017. "Using Hair Growth Activity, Physical Stability, and Safety Tests to Study Hair Tonics Containing Ethanol Extract of Licorice (Glycyrrhiza Glabra Linn.)." International Journal of Applied Pharmaceutics 9(Iii): 44-48.

Vardhani, Afifah K. 2019. "Proceedings of International Conference on Applied Science and Health ICASHA042 Caesalpinia Sappan L: REVIEW ARTICLE Proceedings of International Conference on Applied Science and Health." Proceedings of International Conference on Applied Science and Health (4): 300-305.

Wong, Hendra Wijaya. 2013. "RESEARCH ARTICLE EFFECTIVENESS TEST OF FENUGREEK SEED ( Trigonella Foenum-Graecum L .) EXTRACT HAIR TONIC IN HAIR GROWTH ACTIVITY * Wong Hendra Wijaya , Abdul Mun' Im , and Joshita Djajadisastra Faculty of Pharmacy, University of Indonesia , Depok , Ind." International Journal of Current Research 5(1): 3453-60.

Yuliani, Sri Hartati, Yumi Rahmadani, and Enade Perdana Istyastono. 2016. "Uji Iritasi Sediaan Gel Penyembuh Luka Ekstrak Etanol Daun Binahong Menggunakan Slug Irritation Test." Jurnal Ilmu Kefarmasian Indonesia 14(2): 135-40. http://jurnalfarmasi.or.id/index.php/jifi/article/view/22. 